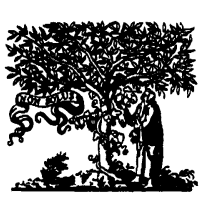

ELSEVIER

\title{
Introduction
}

\section{Introduction to Tech Act}

\author{
Judy Brewer* \\ Massachusetts Assistive Technology Partnership Center, Children's Hospital, 1295 Boylston Street, Suite 310 Boston, \\ MA 02215, USA
}

In this issue we bring you six articles on Tech Act Projects. The Technology Related Assistance for Individuals with Disabilities Act, Public Law 101-407, 103-218, was first passed in 1988 and re-authorized in 1994. It has generated a wide variety of activities directed towards changing the systems through which assistive technology is provided, with the goals of increasing access to assistive technology and making these systems more consumer responsive. The articles in this section provide a chance to visit Tech Act activities in the areas of awareness training, empowerment training, rural outreach, loan fund development, and legal advocacy.

Rachel Wobschall provides an overview of the Tech Act in her interview with Carol Cohen, Program Manager for the Tech Act Projects at the US Department of Education, National Institute of Disability and Rehabilitation Research. Cohen's responses offer a candid and refreshing perspective on the pioneering characteristics of this legislation and the challenges of implementing consumer-responsive, systems change projects in 56 states and territories. Cohen shares with us some of the accomplishments she has observed through her involvement with the Tech Act Projects.

'Empowerment, Advocacy and Self-Advocacy for Assistive Technology' takes a hard look at

\footnotetext{
*Tel.: +1 617 3556380/3557301; fax: +1 6173556345 ; e-mail: jabrewerr@aol.com
}

how the struggle for increased access to assistive technology figures in the dynamics of empowerment of people with disabilities. Amy Goldman and Susan Tachau, of Pennsylvania's Initiative on Assistive Technology (PIAT), compare three approaches to advocacy training for people with disabilities and family members: 'Competence and Confidence: Partners in Policy Making'; 'PIAT Partners'; and 'Becoming a Funding Advocate for Assistive Technology.' They share their conclusions to date regarding the elements of successful advocacy training programs.

Wilhemina Gunther takes us for a drive down the back roads of Illinois and invites us to think about assistive technology service delivery in rural areas - one of the priority areas identified in the 1994 amendments to the Tech Act. Gunther considers the pros and cons of mobile units for rural service delivery in the context of the systemschange mandate of the Tech Act. Regional Centers, Regional Outreach Coordinators and Regional Advisory Committees all come under the microscope at the describes the Illinois Assistive Technology Project's efforts to find the best match for the needs of rural communities in her state.

Joseph Wallace and Kenneth Knorr, of the Virginia Assistive Technology System (VATS), provide a comprehensive picture of loan funds and equipment loan programs in 'Loan Financing for Assistive Technology: Strategies for Development, Current Programs, and Recommendations for the Future.' Loan financing represents one 
approach to increasing the funding options available for people who need assistive technology. VATS, in cooperation with Apogee Research, surveyed 41 loan organizations, and the authors offer a template of design elements identified through their research. Wallace and Knorr describe the demand for loan programs and contrast the implementation of different models in Virginia, Nevada, Maine, South Carolina, and Connecticut.

Jane Gay, of the Iowa Program for Assistive Technology, describes innovative training strategies which her project has used to ensure that people with disabilities at both ends of the age spectrum know about and can access assistive technology. Using a combination of demonstration kits and train-the trainer approaches, Gay developed 'small changes...BIG DIFFERENCES' awareness kits in conjunction with a variety of community organizations. She then watched as these organizations took on ownership of the training programs, generating adjunct projects such as loan closets and low interest loan funds.

'The Texas Assistive Technology partnership and Advocacy, Incorporated: A Cooperative Partnership Between Texas' Tech Act State Project and its Protection and Advocacy System' introduces us to one of the recently formed collaborations between Tech Act Projects and Protection and Advocacy Systems. The authors describe how a process of strategic selection and pursuit of legal casework can link closely with the systems change agenda of a Tech Act Project, and how the Protection and Advocacy System can play a key role in educating people with disabilities about their rights to assistive technology.

These six articles by no means encompass the breadth of Tech Act Project activities, but may serve as a brief introduction to the mandates of the Tech Act and to approaches which some Tech Act Projects are using. We also hope that they may stimulate discussion or increased involvement with Tech Act Projects. As co-editors for the Tech Act section of this issue, Rachel Wobschall, Project Director for the Minnesota STAR Program, and Judy Brewer, Project Director for the Massachusetts Assistive Technology Partnership, often noted that the jobs of journal co-editor and Tech Act Project Director seemed mutually exclusive, given the number of 'systems change barriers' which the average Tech Act Project Director must endeavor to address. We are grateful to the contributors in this section for their thoughtful and thorough discussion of the topics, especially given that many projects are facing difficult transition issues with the impending scheduled sunsetting of the Tech Act, and with recent reductions in funding for Tech Act Projects.

For further information on how to contact the Tech Act Program in your state or territory, contact the RESNA Technical Assistance Project, 1700 North Moore Street, Suite 1540, Arlington, VA 22209-1903, 7035246686 (Voice), 7035246639 (TTY), or via e-mail at nbailey@resna.org.

\section{Biographical Data}

Judy Brewer is Project Director of the Massachusetts Assistive Technology Partnership, a federally-funded project which promotes access to assistive technology for people with disabilities. Her responsibilities include overseeing project activities in the areas of public awareness, information and referral, training and technical assistance, policy development and advocacy. She provides training and technical assistance to local, state, regional and national organizations on the assistive technology needs of people with disabilities and on responsibilities under federal and state laws for provision of assistive technology. Ms. Brewer serves on a number of advisory committees and boards, including the Telecommunications Access Advisory Committee, the National Council on Disability Tech Watch Task Force, the Board of Directors of the Adaptive Environments Center, the Massachusetts Statewide Independent Living Council, and serves as Chair of the RESNA Tech Act SIG. She is the recipient of a RESNA Certificate of Appreciation for efforts related to assistive technology policy development at a national level: and recipient of an Equality of Access and Opportunity Award from the American Foundation for the Blind for advocacy to increase the accessibility of the Windows operating system. 